D| ARTÍCULO

\title{
El camino hacia el reconocimiento legal de la violencia sexual contra la mujer en tiempos de guerra•
}

\section{The path towards the legal recognition of sexual violence against women in times of war}

\author{
Ana Aldave Orzaiz \\ Área de Derecho Internacional Público y Relaciones Internacionales \\ Departamento de Derecho \\ Universidad Pública de Navarra
}

Fecha de recepción 31/05/2020 | De aceptación: 30/09/2020 | De publicación: 28/12/2020

\section{RESUMEN.}

El objetivo de este trabajo es explorar el proceso de configuración de un Derecho Internacional que atienda al fenómeno de la violencia sexual contra las mujeres en contextos de conflictos armados, analizando el alcance del cambio de paradigma logrado en los años noventa con la tipificación y enjuiciamiento de la violencia sexual contra las mujeres en conflictos armados en el ámbito de la justicia penal internacional y, en última instancia, identificando posibles elementos sobre los que seguir avanzando hacia un Derecho Internacional que reconozca un estatus jurídico de las mujeres y huya de la imagen única de la mujer como víctima.

\section{PALABRAS CLAVE.}

conflicto armado, violencia sexual, mujeres, tribunales penales internacionales, Derecho Internacional Humanitario

\section{ABSTRACT.}

This article explores the process of construction of an international legal order law that addresses the phenomenon of sexual violence against women in contexts of armed conflict. It will first analyzing the scope of the paradigm shift achieved in the 1990s with the typification and prosecution of sexual violence against women in armed conflicts in the field of international criminal justice and, ultimately, it will identify possible elements on which International Law should keep making progresses in order to recognize the legal status of women without reproducing the unique image of the woman as a victim.

\section{KEY WORDS.}

Sexual violence, Armed conflict, International Humanitarian Law, International Criminal Courts, Women

\footnotetext{
- El trabajo se desarrolla dentro del proyecto «El logos de la guerra. Normas y problemas de los conflictos armados actuales» (DER201782106-R) financiado por el Ministerio de Economía y Competitividad y dirigido por Roger Campione.
} 
Sumario: 1. Introducción; 2. El simbolismo de la guerra; 3. La violencia sexual en las guerras como constane histórica; 4. La labor de los tribunales penales internacionales; 5. Algunos desafíos para el futuro.

\section{Introducción}

Como ocurre con cualquier forma de conflicto que se dé en el contexto internacional, las guerras vienen caracterizadas por sus propias violencias y riesgos específicos. En las guerras, los civiles -sean hombres o mujeres- son objeto de formas de violencia que son propias a las mismas y distintas a las de otros contextos no bélicos: ataques indiscriminados, desplazamientos, detenciones, esclavitud, etc. A su vez, dentro de esta misma realidad, existe un amplio espectro de factores que determinarán el grado de violencia de cada guerra -como la existencia y estructura de grupos armados, las dinámicas de combate, la cultura, etc- y, por otro lado, una serie de elementos que influirán en la experiencia de esa violencia dentro de un mismo conflicto -tales como la raza, la religión, la clase social, la orientación sexual... o el género ${ }^{1}$-. Ante esta multitud de vetas y bifurcaciones, la experiencia de la violencia que pueden vivir las mujeres durante una guerra se va a ver condicionada por el hecho de ser mujer al menos en un doble sentido: por un lado, lo está en la medida en que existen estructuras de género, anteriores al conflicto y por tanto ajenas al mismo (es decir, comunes a contextos de paz y de guerra), en las cuales mujeres y hombres ocupan una situación desigual de acceso a recursos y poder. Por otro, las guerras actúan no sólo exacerbando estas dinámicas previas, sino incorporando además las suyas propias, añadiendo más violencia, barbarie e impunidad a la ecuación.

Ahora bien, si queremos interesarnos por la respuesta ofrecida por el Derecho Internacional al problema de la violencia sexual contra las mujeres durante los conflictos armados, parece lógico aclarar en primer lugar qué se entiende por violencia sexual y qué se entiende por conflicto armado.

La reflexión acerca de la existencia, la definición y la regulación del fenómeno bélico ha ocupado y sigue ocupando a diversas disciplinas dentro del ámbito de las ciencias sociales, desde la filosofía a la teología, pasando por la política y la sociología. Tantos siglos de reflexión no han evitado que siga

\footnotetext{
${ }^{1}$ Para indagar en la cuestión de la variación de la violencia sexual entre conflictos armados, puede verse WOOD, E.J., "Rape During War is not Inevitable: Variation in Wartime Sexual Violence" en BERGSMO, M., BUTENSCHON, A., WOOD, E.J. (eds.), Understanding and Proving International Sex Crimes, Beijing, Torkel Opsahl Academic Epublisher, 2012, pp. 289-419, especialmente a partir de la página 401.
} 
siendo, a día de hoy, un concepto controvertido y problemático, incluso desde el punto de vista del Derecho. Es sabido que las características de la conflictividad internacional de los últimos años desafían toda definición, distinción y categorización que pudiera haberse alcanzado. Distinciones tan fundamentales como la de guerra y paz, enemigo o criminal, combatiente o civil, se desvanecen a la luz de realidades donde la violencia bélica se despliega sin límites temporales ni geográficos, a menudo incluso sin límites jurídicos, pues estos son cuestionados y acusados de obsoletos. Esta observación no tiene otro ánimo que el de contextualizar debidamente lo que a continuación se recoge sobre la noción de conflicto armado de acuerdo con el Derecho Internacional vigente. Si bien es, en efecto, normativa vigente, no podemos pasar por alto que se trata de una normativa en crisis y seriamente cuestionada, especialmente a raíz del fenómeno de la guerra contra el terrorismo desplegado tras el 11-S de $2001^{2}$.

Volviendo nuestra atención a la norma jurídica, la existencia de un conflicto armado a día de hoy constituye la circunstancia objetiva que permitirá aplicar el Derecho Internacional Humanitario (DIH), de modo que la calificación jurídica de una situación como conflicto armado se hará -o debe intentar hacerse- atendiendo exclusivamente a criterios y elementos fácticos, con total independencia de cualquier consideración subjetiva o política sobre sus actores, sus causas o sus motivaciones ${ }^{3}$. El actual texto de los Convenios de Ginebra establece que éstos serán de aplicación “en caso de guerra declarada o de cualquier otro conflicto armado que surja entre dos o varias Altas Partes Contratantes, aunque una de ellas no haya reconocido el estado de guerra"4. Por otro lado, "en caso de conflicto armado que no sea de índole internacional y que surja en el territorio de una de las Altas Partes Contratantes"5, se aplicará únicamente el artículo 3 de dichos Convenios. El primer supuesto hace alusión a los conflictos armados internacionales, mientras que la segunda categoría hace referencia a los conflictos armados internos (o no internacionales). El texto propugna una determinación eminentemente fáctica de la

\footnotetext{
${ }^{2}$ Puede verse más acerca de la evolución y actual crisis del concepto de conflicto armado en ALDAVE, A. "La crisis de la noción tradicional de conflicto armado en Derecho Internacional: ¿vestigio de una realidad extinta?” en CAMPIONE, R. y RUSCHI, F., Guerra, Derecho y Seguridad en las Relaciones Internacionales, Valencia, Tirant lo Blanch, 2017, pp. 21-44.

${ }^{3}$ Ibid., p., 27.

${ }^{4}$ Artículo 2 común a los cuatro Convenios de Ginebra de 1949. El Convenio se aplicará también en “todos los casos de ocupación total o parcial del territorio de una Alta Parte Contratante, aunque tal ocupación no encuentre resistencia militar". En cuanto al artículo 1 del Protocolo Adicional I, no añade nada nuevo al decir que "el presente Protocolo se aplicará en las situaciones previstas en el artículo 2 común a los convenios. Únicamente aclara que estas situaciones también comprenden las guerras de dominación colonial (en ejercicio del derecho de autodeterminación) y la ocupación extranjera (Artículos 1.3 y 1.4 del Protocolo I)

${ }^{5}$ Artículo 3 común a los cuatro Convenios de Ginebra: "En caso de conflicto armado que no sea de índole internacional y que surja en el territorio de una de las Altas Partes Contratantes cada una de las Partes en conflicto tendrá la obligación de aplicar, como mínimo, las siguientes disposiciones".
} 
existencia de un conflicto armado que, en el caso de los conflictos armados internacionales, se basa en la existencia de hostilidades armadas de facto y en la participación de, al menos, dos Estados enfrentados entre sí ${ }^{6}$. En el caso de conflictos armados internos, la ausencia de una descripción convencional clara de los elementos que lo configuran obligó a la jurisprudencia internacional a elaborar un "test" que permitiera resolver la cuestión relativa a la existencia o no de un conflicto armado y su tipología. Así lo hizo el Tribunal Penal Internacional para la ex Yugoslavia en el caso Tadic condensando el análisis en el examen de un doble requisito: i) la intensidad de la violencia y ii) el grado de organización de las partes ${ }^{7}$. Estos serían desde entonces los principales indicadores que nos permitirían distinguir conflictos armados internos de "meros" disturbios o insurrecciones que pueden darse en contextos de paz.

La violencia sexual, por otro lado, es una violación de derechos que puede ocurrir tanto en un contexto de conflicto armado como en un contexto de paz, pero Naciones Unidas entiende que para hablar de violencia sexual durante una guerra, "dicha violencia -que habrá de ser definida ${ }^{8}$ - debe estar relacionada con el conflicto en el que se incardina y manifiesta:

"La expresión violencia sexual abarca las violaciones, la esclavitud sexual, la prostitución forzada, los embarazos forzados, la esterilización forzada y todos los demás actos de violencia sexual de gravedad comparable contra mujeres, hombres o niños que tienen una vinculación directa o indirecta (temporal, geográfica o causal) con un conflicto. Esa vinculación con el conflicto puede manifestarse en el perfil del autor, el perfil de la víctima, el clima de impunidad, la situación de colapso del Estado o las dimensiones transfronterizas" $"$.

Esta descripción del fenómeno hecha por Naciones Unidas no asocia la violencia sexual únicamente con las mujeres; más bien al contrario, reconoce expresamente que puede ir dirigida contra mujeres,

\footnotetext{
${ }^{6}$ La cuestión principal aquí será valorar, no el grado de intensidad de las hostilidades, sino el grado de participación de un Estado en las mismas, especialmente cuando dicha participación se oculta y se diluye tras la actuación, más visible, de grupos no estatales.

7 Tribunal Penal Internacional ex Yugoslavia, Caso No IT-94-1-A, Prosecutor v DuskoTadic a/k/a "Dule”, Sentencia del 7 de mayo de 1997, párrafo 562.

${ }^{8}$ La violencia sexual ha sido definida por la Organización Mundial de la Salud como aquella violencia que abarca "actos que van desde el acoso verbal a la penetración forzada y una variedad de tipos de coacción (desde la presión social y la intimidación a la fuerza física". ORGANIZACIÓN MUNDIAL DE LA SALUD, Comprender y abordar la violencia contra las mujeres, Violencia sexual, Washington DC, 2013, p. 1.

9 Resolución del Consejo de Seguridad de 14 marzo 2013 2014/184, Informe del Secretario General de Naciones Unidas "Violencia sexual relacionada con los conflictos".
} 
hombres, niñas o niños. En efecto, los varones también han sido y son víctimas de la violencia sexual en las guerras. Sin embargo, lo cierto es que es muy minoritaria en comparación con la violencia que han sufrido históricamente y sufren actualmente las mujeres. Por otro lado, como apunta Sánchez de Madariaga, las agresiones que ejercen hombres contra otros hombres y niños estarían reproduciendo en última instancia patrones que son comparables a los que subyacen a la violencia sexual contra mujeres: mediante dicha violencia, los perpetradores manifiestan y ejercen relaciones de fuerza y de poder con el objetivo no sólo (o no tanto) de buscar placer inmediato, sino más bien de humillar a la víctima y al colectivo al que pertenece ${ }^{10}$. De la misma manera, tampoco las mujeres están exentas de cometer actos de violencia sexual ni dentro ni fuera de las guerras. Pero, de nuevo, se trata de una violencia mucho menos frecuente ${ }^{11}$. Se estima que en un $25 \%$ de las violaciones en grupo perpetradas por miembros del Frente en Sierra Leona (que suponían un 75\% del total de violaciones de la guerra que asoló el país), participaron mujeres combatientes ${ }^{12}$. Las mujeres soldado y oficiales también participan en la vigilancia y los interrogatorios de prisioneros, que pueden incluir tortura o violencia sexual. Coco Fusco ha estudiado cómo el ejército de EEUU utiliza a las mujeres de sus fuerzas armadas para interrogar a presos musulmanes en una táctica autorizada que se denomina Invasion of Space by a female: se pide a las mujeres que muestren abiertamente su sexualidad femenina para provocar a los prisioneros y quebrar su voluntad ${ }^{13}$.

Estas formas de ejercer violencia responden de un modo u otro a roles y estereotipos de género que perpetúan una concepción de lo masculino y de lo femenino que, como veremos, han influido en gran

\footnotetext{
10 SÁNCHEZ DE MADARIAGA, H., "Género y guerras: la criminalización de la violencia sexual”, Journal of Feminis Gender and Women studies, Vol. 3, 2016, pp. 45-55, p. 46. Sobre violencia sexual contra los hombres, véase SIVAKUMARAN, S., "Sexual violence against men in armed conflict", European Journal of International Law, Vol. 18 (2), 2007, pp. 253-276. Sobre el predominio de los hombres en la perpetración de ciertos tipos de delitos, véase STRAUS MURRAY, A., "Thirty years of denying the evidence on gender simmetry" en Partner Violence: implications for prevention and treatment. Partner Abuse, Vol. 1, 2010, pp. 332-362; y PEARCE, J., "Bringing violence 'back home': gender socialization and the transmission of violence through time and space" en ANHEIER, H., KALDOR, M. y GLASIUS, M. (eds.), Global Civil Society, Londres, Sage Publications, 2006/7, pp. $42-60$.

${ }^{11}$ SÁNCHEZ DE MADARIAGA, H., “Género y guerras...”, Op. Cit., p. 52.

${ }^{12}$ Estos datos se obtienen de un análisis elaborado por Dana Kay Cohen y citado en WOOD, E.J., "Rape during war is not inevitable: variation in wartime sexual violence" en BERGSMO, M., BUTENSSCHON, S.A. y WOOD, E. J. (eds.), Understanding and Proving International Sex Crimes, Beijing, Torkel Opsahl Academic Epublisher, 2012, pp. 389-419, p. 401. El trabajo de Dana Kay Cohen, según apunta Wood, se recoge en el paper no publicado "Female combatants and violence in armed groups: women and wartime rape in Sierra Leone", que forma parte del trabajo de análisis de datos no publicado de ASHER, J. (ed.) \& Human Rights Data Analysis Group of Benetech, Sierra Leone War crimes documentation survey database V.2, de 2004.

${ }^{13}$ FUSCO, C., "Invasion of Space by a Female", en FRIEDMAN, J. y VALENTI, J. (eds.) Yes means yes! Visions of Female Sexual Power and a World without Rape, Berkeley, Seal Press, 2008, pp.127-139. Sobre las mujeres en el ejército de EE.UU., véase RAYAS, L., "Las mujeres soldadas en las nuevas guerras de los siglos XX y XXI" en QUESADA, F., (ed.), Mujeres y guerra. Cuerpos, territorios y anexiones, Madrid, Biblioteca Nueva, 2014, pp. 229-257.
} 
medida en la manera en que se ha abordado el problema de la violencia sexual durante las guerras ${ }^{14}$. Sin embargo, la necesidad de un estudio autónomo de la violencia sexual contra las mujeres durante una guerra no sólo se justifica por su mayor incidencia, sino porque guerra y género confluyen en este fenómeno incorporando claves de análisis específicas: la violencia sexual contra la mujer en tiempos de guerra es una dimensión de la violencia en la que se manifiesta de forma particularmente visible cómo la mujer (y, concretamente, su cuerpo) se transforma en objeto de y para la acción, reproduciendo dinámicas de dominación, poder y cosificación que, si bien son comunes a otros contextos, se ven exacerbados ante la presencia del conflicto bélico.

\section{El simbolismo de la guerra}

El papel de las guerras en la construcción e identificación de mujeres y hombres con distintos roles no es, ni mucho menos, una característica propia y novedosa de nuestro tiempo y sus "nuevas guerras". Basta con leer relatos como éste de Tito Livio para constatar cómo el simbolismo de la guerra se remonta a tiempos tan remotos de la historia como el origen de Roma:

“El Estado de Roma se había vuelto tan fuerte que su potencial su grandeza amenazaba con durar sólo una generación ya que, por la ausencia de mujeres, no había ninguna esperanza de descendencia; (...) se dio la señal convenida y los jóvenes romanos corrieron desde todas las direcciones para llevarse a las doncellas que estaban presentes. La mayor parte fue llevada de manera indiscriminada; pero, algunas, especialmente hermosas, que habian sido elegidas para los patricios principales, fueron llevadas a sus casas por plebeyos a quienes se les habia encomendado dicha tarea" ${ }^{15}$.

“Fue entonces cuando las mujeres sabinas, cuyos secuestro había llevado a la guerra, despojándose de todo temor femenino en su aflicción, se lanzaron en medio de los proyectiles con el pelo revuelto y las ropas desgarradas.(...) Trataron de impedir la lucha y calmar las pasiones excitadas apelando a sus padres en uno de los ejércitos y a sus maridos en el otro.(...)"Si estáis hastiados de estos lazos de parentesco, de estas uniones matrimoniales, volcad vuestra ira sobre nosotras; somos nosotras la causa de la guerra, somos nosotras las que habremos herido y matado a nuestros maridos y padres. Mejor será para nosotras morir antes que vivir sin el uno o el otro, como viudas o como huérfanas.

\footnotetext{
${ }^{14}$ SÁNCHEZ, E., “Género y guerras...”, Op. Cit..., p. 53.

${ }^{15}$ LIVIO, T., Historia de Roma desde su fundación. Vol. 1, Libros I a X, Ab urbe condia, p.13.
} 
(...) No sólo resultó que se hizo la paz; ambas naciones se unieron en un único estado. (...) La paz gozosa, que puso un final repentino a tan deplorable guerra, hizo a las sabinas aún más queridas a sus maridos y padres, y sobre todo al propio Rómulo"16.

Este pasaje, que sitúa la violación de las sabinas nada más y nada menos que en los orígenes de la mismísima Roma, expresa palmariamente los roles de género básicos que, originados como en este caso con ocasión de una guerra, traspasan la propia guerra para reproducirse en contextos de paz. Los varones son guerreros mientras que las mujeres, aunque inicialmente aparecen como víctimas (es el agravio a las mujeres el hecho que detona la violencia), pronto pasan a ser representadas como causantes de la guerra (ellas mismas asumen la responsabilidad y la culpa al decir "nosotras somos la causa de la guerra) para, finalmente, ser presentadas como pacificadoras ("y entonces las sabinas irrumpieron para separar a los contendientes y poner fin a su furor" ${ }^{17}$.

Como señala Carol Cohn, la guerra está profundamente marcada por el género no sólo en la práctica sino también de forma simbólica ${ }^{18}$. La guerra es el entorno paradigmático en el que el hombre puede demostrar fuerza, coraje, poder, disciplina; valores y virtudes identificados y vinculados con lo masculino en la mayoría de las culturas y que explican por qué la guerra ha sido considerada tradicionalmente como el epítome de lo masculino. Simultáneamente, mientras la guerra ofrece la oportunidad de presentar al hombre como guerrero, se concibe a la mujer o bien como cuidadora (madre-esposa-enfermera) o bien como víctima-objeto de los guerreros. Así, la propia prevalencia de las guerras en la historia de cualquier sociedad, sumada a las acusadas diferencias de género que en ellas se desatan, dan una idea aproximada de la relevancia y papel que han jugado las guerras en la construcción de los roles y estereotipos de género. Como afirma Goldstein, el género moldea la guerra y a la inversa, la guerra moldea el género ${ }^{19}$.

\section{La violencia sexual en las guerras como constante histórica}

\footnotetext{
${ }^{16}$ Ibid, p. 16

17 Véase SÁNCHEZ DE LA MADARIAGA, E. “Género y guerras...”, Op. Cit..., p. 46.

${ }_{18} \mathrm{COHN}, \mathrm{C}$. "Hacia un marco conceptual de la violencia contra las mujeres en las guerras", en COHN, C. (ed.).Women and Wars, Cambridge, Ed. Polity Press Ltd, 2014. Edición española Las mujeres y las guerras, Ed. ICIP, Barcelona 2015, p. 63.

19 GOLDSTEIN, J., War and Gender: How Gender Shapes the War System and Viceversa, Cambridge, Cambridge University Press, 2001, pp. 1-34.
} 
Sólo la violencia sexual contra las mujeres en conflictos armados documentada en el siglo XX da cuenta de la magnitud del problema. Según el Tribunal Penal Militar Internacional para el Lejano Oriente, más de 20.000 mujeres fueron violadas sólo durante la masacre de Nankín en 1937. Para evitar que la violencia sexual se produjera de manera "descontrolada" en los territorios ocupados por el ejército japonés como había ocurrido en Nankin, pero asumiendo que las mujeres (su cuerpo) eran "necesarias" para aliviar y elevar la moral de los soldados, el gobierno japonés "regularizó" esta práctica esclavizando sexualmente a entre 80.000 y 200.000 mujeres durante la segunda guerra mundial, las llamadas “confort wifes". Tras la invasión de Polonia, la creación de burdeles con niñas y jóvenes de territorios ocupados se normalizó en buena parte de Europa. Se estima que el ejército estadounidense fue responsable de unas 13.000 violaciones a mujeres francesas, inglesas y alemanas durante la Segunda Guerra Mundial, y entre 100.000 y un millón de mujeres alemanas pudieron haber sido víctimas de violaciones masivas por parte del Ejército soviético ${ }^{20}$.

Sin embargo, ni el Tribunal Penal Militar Internacional de Núremberg, ni el Tribunal Penal Militar Internacional para el Lejano Oriente incorporaron en sus estatutos la violencia sexual como crimen internacional, por lo que ninguno de los acusados en estos procesos fue responsabilizado por crímenes de naturaleza sexual. A pesar de que la violencia contra las mujeres aparecía ampliamente documentada en ambos procesos, las palabras "violación” y "mujeres” no figuraron en ningún título ni subtítulo de las 732 páginas resultantes de su sumario ${ }^{21}$

Indagando en el marco jurídico de la época, encontramos que las Convenciones de la Haya de 1899 y 1907 tan sólo habían dedicado un único artículo a exigir respeto y protección para el honor de la familia. Y es únicamente desde este problemático prisma -el del honor de la familia- desde donde cabría entender cierta protección implícita respecto de la violencia sexual, ya que a finales del siglo

${ }^{20}$ Para un repaso del papel del Ejército Rojo, véase: NAIMARK, N. The Russians in Germany: A History of the Soviet Zone of Occupation, 1945-1949. Boston, Harvard University Press, 1995. Sobre la actuación de Japón, véase SARAH SOH, C., «The Comfort Women: Sexual Violence and Postcolonial Memory in Korea and Japan», American Anthropologist, Vol. 112, No. 2, 2010 , pp. $337-338$. Sobre la actuación del Ejército de EEUU: ROBERT LILLY, J.,Taken by Force: Rape and American Girls in Europe during World War II, Londres, Palgrave Macmillan, 2007.

21 ASKIN, K.D., "Prosecuting Wartime Rape and Other Gender-Related Crimes under International Law: extraordinary advances, enduring obstacles", Berkeley Journal of International Law, Vol. 21, Issue 2, 2003, pp. 288-349, cita en 294-295. La autora insiste en la brecha que existe entre los abundantes datos sobre agresiones sexuales que aparecen en los procesos y la ausencia de referencias a mujeres y violencia sexual en los índices, y argumenta que el tribunal de Nuremberg podía haber juzgado crímenes sexuales si hubiera existido voluntad para hacerlo. Ver también de la misma autora ASKIN, K., War crimes against women: prosecution in international war crimes tribunals, La Haya, Martinus Nijhoff Publishers, 1997, pp. 129-163 
XIX y comienzos del XX era común concebir la violación como un atentado al honor familia o a la honra del marido o del padre ${ }^{22}$.

Fruto del trauma provocado por la sacudida de dos guerras mundiales en menos de dos décadas, la comunidad internacional se afanó en la elaboración de los Convenios de Ginebra de 1949, el corpus jurídico más importante y vigente a día de hoy aplicable a situaciones de conflictos armados. Dichos convenios conforman un total de 378 artículos distribuidos en cuatro instrumentos en los que se establecen las reglas, garantías, derechos y deberes fundamentales en caso de conflicto $\operatorname{armado}^{23}$. De todos ellos, únicamente hay uno, el artículo 27 del Cuarto Convenio ${ }^{24}$, que dispone que las violaciones o la prostitución forzada son actos que atentan contra el "pudor" de las mujeres contrarios al DIH; pero no los menciona expresamente como "infracción grave" del DIH y, por tanto, no conllevan automáticamente la responsabilidad penal internacional de quien los perpetra ${ }^{25}$. Se arguyó que los delitos de lesa humanidad y los crímenes de guerra eran categorías jurídicas generales y superiores en las que las conductas sexuales, como tantas otras, quedaban subsumidas ${ }^{26}$. Pero lo cierto es que, precisamente en una época en la que, por fin, el Derecho Internacional comenzaba a prestar atención a la regulación de las guerras y a la protección de los civiles de los efectos devastadores de las mismas, el hecho de que las violaciones, la prostitución forzada y otros actos de violencia sexual contra las mujeres no fueran expresamente tipificadas como crímenes puede tener más que ver con razones y dinámicas sociales de fondo 27.

\footnotetext{
${ }^{22}$ Convención II de la Haya de 1899 relativa a las leyes y usos de la guerra, artículo 46 y Reglamento relativo a las leyes y costumbres de la guerra terrestre.

${ }^{23}$ El contenido de los Convenios de Ginebra es en su gran parte aplicable sólo a conflictos armados internacionales. Únicamente el artículo 3, común a los 4 de Convenios, contiene el régimen (por tanto, muy exiguo) que opera en caso de conflicto armado interno.

${ }^{24}$ Convenio de Ginebra del 12 de agosto de 1949 relativo a la protección debida a las personas civiles en guerra, artículo 27.

25 Toda violación de una norma de DIH recogida en los convenios conlleva la obligación de tomar medidas para su cese. Pero sólo aquellas violaciones expresamente categorizadas en los convenios como "infracciones graves" activan la responsabilidad penal internacional. Las infracciones graves según los Convenios de Ginebra y sus protocolos adicionales son el homicidio intencional, la tortura o tratos inhumanos, los experimentos biológicos, atentados graves contra la integridad física o la salud, destrucción y apropiación de bienes no justificadas por necesidades militares y efectuadas a gran escala, ilícita y arbitrariamente, forzar a un prisionero de guerra a servir en las fuerzas armadas enemigas, privar intencionalmente a un prisionero de guerra de su derecho a ser juzgado legítima e imparcialmente, la deportación de civiles, la toma de rehenes y la detención ilegal de personas protegidas.

${ }^{26}$ RÍOS, J. Y BROCATE, R. "Violencia sexual como crimen de lesa humanidad: los casos de Guatemala y Perú, Revista CIDOPB d'Affairs Internationals, No. 117, pp. 79-99, p. 85.

${ }^{27}$ CHINKIN, C., "Rape and Sexual Abuse of Women in International Law”, European Journal of International Law, Vol. 5, No.2, 1994, pp. 326-341.
} 
En primer lugar, calificar como atentados a la honra femenina y al honor de la familia las violaciones y abusos sexuales como se hizo en los Convenios de la Haya, si bien constituía un enfoque consecuente con la concepción de aquella época sobre los roles y valores de género, dificultaba su percepción como crímenes contra las mujeres y, por tanto, su ulterior enjuiciamiento. Hasta el siglo XX, la concepción del honor de la mujer que reinaba en el marco social y cultural de la época (impregnando por tanto el marco legal) nada tenía que ver con la dignidad de la mujer, sino que concebía dicho bien jurídico como un valor patrimonial titularidad del varón o de la familia ${ }^{28}$. Más tarde, puede que la mala conciencia de los dos bandos contendientes - puesto que tanto vencedores como vencidos se sabían partícipes de actos de violencia sexual- jugase un papel en el silencio de los estatutos de los tribunales militares de Núremberg respecto a la violencia sexual. Pero esta discutible aunque posible "mala conciencia" en modo alguno es explicación suficiente. El desinterés (o, quizás, la pasividad) hacia la violencia sexual, en una época en la que la consternación por las barbaridades de las guerras cuajaba al fin en regulaciones jurídicas y en un nuevo ius in bello, sugiere que dichas conductas -a diferencia de otras que comenzaban a considerarse y a reconocerse como inadmisibles- habían sido asimiladas en el imaginario colectivo o bien como "males necesarios" durante la guerra o bien como "males menores", al menos en comparación con otros sufrimientos acarreados por las guerras.

\section{La labor de los tribunales penales internacionales}

A pesar de que la violencia sexual contra las mujeres había sido un elemento habitual en la violencia bélica a lo largo de la historia y en particular en las dos guerras mundiales, ni la constitución de los tribunales del Lejano Oriente y Núremberg, ni tampoco la cristalización del Derecho Internacional Humanitario de la mano de los Convenios de Ginebra trajo consigo la tipificación y penalización expresa de esta forma de violencia. Hubo que esperar hasta la última década del siglo XX para asistir a los primeros avances en el camino -escasamente recorrido hasta entonces- hacia la justicia internacional por delitos de violencia sexual contra las mujeres y las niñas durante las guerras.

En 1992, las violaciones masivas de mujeres y embarazos forzados con fines de "limpieza étnica" en la guerra de Bosnia-Herzegovina ocasionaron la intervención del Consejo de Seguridad de Naciones

28 Véase la tesis de PASCUAL I LAGUNAS, E,."La violencia sexual en los conflictos armados: una reflexión crítica sobre su configuración jurídica, jurisprudencial y doctrinal”, 2017, Universidad Autónoma de Barcelona. 
Unidas, que el 18 de diciembre de 1992 emitía una Resolución en la que se declaraba "consternado" ante "las detenciones y violaciones sistemáticas, masivas y organizadas de mujeres, en particular, de mujeres musulmanas, en Bosnia y Herzegovina" y exigía "el cierre inmediato de los campos de concentración" pero, en particular, "de los campamentos de mujeres" 29 . Dos meses después, en febrero de 1993, dispuso el establecimiento del Tribunal Penal Internacional para la ex Yugoslavia ${ }^{30}$. El artículo 5 del Estatuto del dicho Tribunal incluía la violación en el listado de conductas que serían consideradas como "crímenes de lesa humanidad" ${ }^{31}$. Era la primera vez que la violencia sexual en un conflicto armado era considerada un delito internacional. Un año después, en 1994, el Consejo de Seguridad establecería el Tribunal Penal Internacional para Ruanda para investigar y castigar los crímenes internacionales llevados a cabo en el conflicto armado de Ruanda ese mismo año ${ }^{32}$. De nuevo, la violencia sexual quedaba expresamente tipificada como delito de lesa humanidad en el artículo 3 de los Estatutos del Tribunal ${ }^{33}$. Tras siglos de silencio e impunidad, la incorporación de estos actos a la lista competencias de unos tribunales penales internacionales representaba no sólo un auténtico hito histórico y social sino, además, un precedente judicial que resultaría decisivo en el futuro tratamiento de dichos crímenes en otros foros y $\operatorname{conflictos}^{34}$.

La primera condena por parte de una corte penal internacional por violencia sexual llegó de la mano del Tribunal Penal Internacional para Ruanda (TPIR) el 2 de septiembre de 1998 en el caso contra Jean Paul Akayesu ${ }^{35}$. Akayesu había sido alcalde de Taba, lugar en el que, bajo sus órdenes y supervisión, se habían producido algunos de los crímenes sexuales más graves contra la población tutsi. La sentencia marcó un punto de inflexión porque concluyó que, a la luz de los hechos probados, las formas de violencia sexual contra las mujeres no sólo constituían crímenes de lesa humanidad (una posibilidad ya tipificada en los estatutos), sino que habían sido empleadas además como instrumento para el genocidio de una parte de la población.

\footnotetext{
${ }^{29}$ Consejo de Seguridad, Resolución 798 de 18 de diciembre de 1992.

${ }^{30}$ Consejo de Seguridad, Resolución 808 de 22 de febrero de 1993.

${ }^{31}$ Consejo de Seguridad, Resolución 827, 25 de mayo de 1993.

${ }^{32}$ Consejo de Seguridad, Resolución 955 de 8 de noviembre de 1994

${ }^{33}$ Ibid. Anexo. Artículo 3.g.

${ }^{34}$ ASKIN, K.D., "Prosecuting Wartime Rape and Other Gender-Related Crimes...", Op .Cit., p. 288

35 Tribunal Penal Internacional para Ruanda, Caso No ICTR-96-4-T, Fiscal vs. Jean Paul Akayesu, Sentencia del 2 de septiembre de 1998. En adelante, Caso Akayesu.
} 
La expresa tipificación de la violación en el artículo 3 del Estatuto del TPIR como posible acto constitutivo de crímenes contra la humanidad, proporcionaba a fiscalía y tribunal un punto de partida histórico $^{36}$. Sin embargo, no existía en el ordenamiento jurídico internacional una definición del término "violación", de modo que la Sala se enfrentó a la necesidad de elaborar una definición que le permitiera cotejar las conductas de los acusados; dicha definición sentaría un importante precedente judicial:

"El tribunal considera que la violencia sexual -en la que se incluye la violación- es cualquier acto de naturaleza sexual que se comete contra una persona en circunstancias coactivas. La violencia sexual no está limitada al a invasión física del cuerpo humano y puede incluir actos que no implican la penetración ni el contacto físico. El incidente que describió la Testigo KK en el que el acusado ordenó a los Interahamwe que desvistieran a una estudiante a la fuerza y que la obligaran a hacer gimnasia desnuda en el patio público del edificio de la comuna, en frente de la multitud, constituye violencia sexual" 37 .

Con esta construcción de la "violencia sexual", el tribunal ponía el acento en la atmósfera coercitiva independientemente del sexo de la víctima, e independientemente de que hubiera o no contacto físico-, subrayando además que dicha coacción no tenía por qué implicar fuerza, violencia o contacto físico, sino que podía venir dada por el hecho de desarrollarse en un contexto de conflicto armado.

La definición de "violación" - un tipo específico de violencia sexual- también hubo de ser expresamente construida por el tribunal. En primer lugar, la Sala señaló que los elementos centrales del delito de violación no se podían capturar en una descripción mecánica de objetos y partes del cuerpo ${ }^{38}$. A partir de ahí, concluyó que debía definir la violación “como una invasión física de naturaleza sexual, cometida contra una persona bajo circunstancias coactivas ${ }^{39 "}$ y continuó subrayando que, "al igual que la tortura, la violación se usa para propósitos como la amenaza, la degradación, la humillación, la

\footnotetext{
${ }^{36}$ Párrafos 584 y 585 Caso Akayesu. El propio Tribunal aprovechó para clarificar que la lista elaborada en el artículo 3 no era una lista exhaustiva, de modo que cualquier otro acto podía constituir un crimen de lesa humanidad si cumplían los demás elementos de dicho tipo penal.

${ }^{37}$ Ibid., párrafo 688 .

${ }^{38}$ Ibid., párrafo 597.

${ }^{39}$ Ibid., párrafo 598.
} 
discriminación, el castigo, el control o la destrucción de una persona" ${ }^{40}$. El Tribunal apuntó que, si bien las jurisdicciones nacionales habían definido la violación como "relación sexual no consentida", una definición más amplia, como la que esta corte proponía, se antojaba necesaria en el ámbito internacional, y ésta debía incluir "actos que involucren la inserción de objetos y/o el uso de orificios del cuerpo no considerados inherentemente sexuales"41. Una vez establecidas las definiciones y premisas necesarias, y tras valorar los hechos a la luz de la evidencia presentada, el tribunal finalmente reconoció que las violaciones habían sido perpetradas como "parte integral de un proceso de destrucción del enemigo" 42 que era constitutivo de crímenes de guerra, crímenes contra la humanidad y genocidio.

Pero la trascendencia de esta sentencia no se limitó a la vinculación de la violencia sexual con los crímenes contra la humanidad. Hubo otro elemento que contribuyó a elevar dicha sentencia a la categoría de hito jurídico, y no es otro que el de la construcción de un razonamiento según el cual las violaciones debían ser castigadas en tanto en cuanto habían sido un instrumento para llevar a cabo el genocidio. Este enfoque dio entrada al tratamiento de la violación como arma de guerra, una conclusión bajo la cual subyacía el reconocimiento previo de que el cuerpo de la mujer estaba siendo usado como campo de batalla. En este sentido, la Sala consideró probado que la violación de las mujeres tutsi se produjo de manera sistemática contra todas las mujeres tutsi -y sólo contra ellas- justamente porque eran tutsi y porque eran mujeres, con el objetivo de humillar, desmoralizar y exterminar no sólo a ellas, víctimas directas, sino al conjunto de la población tutsi.

Dos meses después de la sentencia del TPIR en el caso Akayesu, el Tribunal Penal Internacional para la ex Yugoslavia (TPIY) fallaba en el caso Celebici sumando nueva jurisprudencia en el ámbito de la violencia sexual contra las mujeres durante las guerras ${ }^{43}$. El tribunal se ocupaba en esta ocasión de los hechos ocurridos en el centro de detención del pueblo de Celebici, en Bosnia y Herzegovina, durante 1991. Los aspectos más relevantes de este caso aluden a la interpretación de la violación como un

\footnotetext{
${ }^{40}$ Ibid.

${ }^{41}$ Ibid., párrafo 686. Mediante el ejemplo extraído de uno de los testimonios dados ante el tribunal, la cámara estipuló que "introducir una pieza de madera en los órganos sexuales de una mujer tumbada constituye violación en vista del tribunal"

42 Ibid., párrafos 731 y 732.

43 Tribunal Penal Internacional para la ex Yugoslavia, Caso No IT-96-21-IT, Fiscal vs. ZejnilDelalic, ZdravkoMucic alias "Pavo", HazimDelic, EsadLandzo alias “Zenga” (Celebici), Sentencia del 16 de noviembre de 1998. En adelante, Caso Celebici.
} 
medio o instrumento para la tortura, tipificada en los estatutos del tribunal como uno de los crímenes internacionales de su competencia. El Fiscal había acusado a Delic de delito de tortura en virtud del artículo 2 del Estatuto del TPIY y la Sala, basándose en la Convención contra la Tortura (CCT), interpretó que cualquier forma de violencia sexual que cumpliera con los elementos establecidos por la CCT como constitutivos de tortura, debía ser considerada como delito de tortura conforme al Estatuto $^{44}$. Tras examinar la jurisprudencia de la Corte Interamericana de Derechos Humanos y del Tribunal Europeo de Derechos Humanos, el Tribunal elaboró dichos requisitos señalando cuáles debían ser los elementos esenciales: i) acto u omisión que cause dolor o sufrimiento grave, ya sea de carácter físico o mental; ii) infligido intencionadamente; iii) con los propósitos de obtener información o una confesión, castigar a la víctima, intimidar; iv) ese acto u omisión debe ser cometido por un funcionario público $^{45}$. Una vez hubo examinado los hechos, el tribunal concluyó que el objetivo de las violaciones en el campo de Celebici descritas y probadas durante el proceso era, efectivamente, el de coaccionar e intimidar a las víctimas para que proporcionaran información, así como castigarlas por los delitos de sus maridos o bien por su actitud poco colaborativa. El hecho de que dichos actos se cometieran además en un campo de prisioneros contribuyó, además, a crear una atmósfera de temor y coacción entre todos los internos ${ }^{46}$, hecho que, según la Corte, Delic conocía y usó a su favor para difundir un terror colectivo y lograr así la subordinación de las víctimas ${ }^{47}$.

A finales de ese mismo año, en diciembre de 1998, conocíamos la sentencia del TPIY en el caso contra Ando Furundzija, un comandante del ejército croata acusado de violar las leyes de la guerra durante los interrogatorios a los que sometía a la población bosnia-musulmana ${ }^{48}$. El primer elemento que da una idea de la relevancia de este caso es que atendía cargos por múltiples violaciones contra una única mujer. La víctima -a diferencia del resto de casos ya enjuiciados o pendientes de enjuiciamiento-, no era un grupo ni un colectivo. La sentencia, por tanto, sentó un precedente de gran trascendencia al confirmar que la violencia sexual cometida contra una única mujer, una sóla, podía constituir una

\footnotetext{
44 "Para que la violación sea incluida dentro del delito de tortura, debe reunir cada uno de los elementos de dicho delito". Caso Celebici, párrafo 480. "En los casos en que la violación u otras formas de violencia sexual reúnen los criterios antes mencionados, deberán constituir delito de tortura". Ibid., párrafo 496.

${ }^{45}$ Ibid., párrafo 494.

${ }^{46}$ Ibid., párrafo 941

${ }^{47}$ Idem.

${ }^{48}$ Tribunal Penal Internacional para la ex Yugoslavia, Caso No IT-95-17/1-T, Fiscal vs. Anto Furundzija, Sentencia del 10 de diciembre de 1998. En adelante, Caso Furundzija.
} 
violación grave de las leyes de la guerra y, por tanto, un crimen internacional ${ }^{49}$. Era también la primera vez en la que se abordaban las violaciones como crimen autónomo, sin necesidad de que estuvieran supeditadas a otras intenciones últimas y, por tanto, a otras categorías "superiores", como el genocidio, la tortura o los crímenes de lesa humanidad. La fiscalía había acusado a Furundzija de violación de las leyes de la guerra en virtud del artículo 3 del Estatuto. Las "violaciones", "agresiones sexuales" u otros actos de violencia sexual no aparecían en la lista de actos que según dicho artículo constituían una violación de las leyes de la guerra, pero el tribunal sentenció que dicho artículo sí cubría los atentados contra la dignidad de la persona, y era ahí donde un acto como la violación encontraba cabida ${ }^{50}$.

Los procesos de incorporación de un enfoque de género al Derecho Internacional Humanitario y de configuración de una jurisdicción penal internacional competente para conocer de los crímenes internacionales más graves culminaron en 1998 con la redacción del Estatuto de Roma, el primer tratado internacional que reconocería la violación, la esclavitud sexual, la prostitución forzada, el embarazo forzado, la esterilización forzada, las persecuciones basadas en el género, el tráfico de personas y la violencia sexual como crímenes de guerra y de lesa humanidad (y, en algunos casos, de genocidio). Éste es el Estatuto que vincularía a la que, por virtud de dicho tratado internacional, sería desde ese momento la primera corte penal internacional permanente.

Según establece el preámbulo del Estatuto, la Corte únicamente tiene competencia sobre aquellos crímenes que "desafían la imaginación, conmueven la conciencia de la humanidad" y "constituyen una amenaza para la paz, seguridad y bienestar de la humanidad" 51 . En esencia, lo que con estas palabras se está señalando es que serán competencia de la jurisdicción penal internacional únicamente las vulneraciones de derechos más graves, aquellas que por su especial naturaleza y gravedad, como dice Anne-Marie Slaughter, "golpean a la humanidad entera" ${ }^{2}$. Que el Estatuto considerase que los crímenes con componente sexual contra las mujeres satisfacían dicho estándar -“conmover la

\footnotetext{
${ }^{49}$ Caso Furunzija párrafos 124-130.

50 Ibid., párrafo 173.

${ }^{51}$ Estatuto de Roma de la Corte Penal Internacional (CPI), 17 de julio de 1998.

52 SLAUGHTER A.M., "Definig the limits: Universal Jurisdiciion and International Courts", en MACEDO, S. (ed.), Universal jurisdiction: national courts and the prosecution of serious crimes under international law, Philadelphia, University of Pennsylvania Press, 2006, pp. 168-190.
} 
conciencia de la humanidad"-, era sin duda una prueba definitiva de que el paradigma de la resignación, la indiferencia y el silencio había llegado a su fin.

Pese a que la definición de género en el Estatuto de Roma no está libre de controversia ${ }^{53}$, y a pesar del camino que aún queda por recorrer -y al que me referiré en las próximas páginas-, lo cierto es que el Estatuto, más allá de la categorización y tipificación jurídica de la violencia sexual como delito internacional, trata de incorporar el género de manera transversal a todo funcionamiento de la Corte, desde la presencia de asesores jurídicos específicos para cuestiones de género, a la instauración de un especial mandato de género de la fiscalía, pasando por la protección a las víctimas de violencia sexual durante todo el proceso $^{54}$. Pero uno de los elementos más determinantes a la hora de enjuiciar los crímenes de naturaleza sexual no es otro que la Fiscalía y, concretamente, la voluntad de quien esté al frente de la Fiscalía. El artículo 54.1 del Estatuto exige a la Fiscalía que preste especial atención a los crímenes de violencia sexual, violencia de género y violencia contra los niños. Será la Fiscalía quien, en cumplimiento con dicho mandato, llevará a cabo las investigaciones oportunas para -y aquí está el conflicto- decidir qué cargos deben o pueden ser presentados ante el Tribunal. En esta decisión, la Fiscalía debe realizar un ejercicio de "priorización" que puede basar en diversos criterios, y uno de los criterios más determinantes en la práctica suele ser el de la evidencia probatoria recopilada ${ }^{55}$. El problema que se origina a la hora de enjuiciar o no los delitos de naturaleza sexual es que éstos casi siempre dependen de la declaración de testigos o víctimas, evidencias probatorias que resultan especialmente difíciles de conseguir. Esta circunstancia, unida a la complejidad inherente a los casos de los que conoce la Corte, hace que a la hora de seleccionar y decidir los crímenes por los que se presentarán cargos, resulte decisiva no sólo la estrategia y destreza de la Fiscalía, sino también su compromiso personal con este mandato.

\section{Algunos desafíos para el futuro}

Puede que los avances jurídicos expuestos en estas páginas constituyan buenos ejemplos de cómo el Derecho es siempre, como apunta Campione, un saber referido a una realidad social e histórica que no

\footnotetext{
${ }^{53}$ El artículo 7.2 del Estatuto de Roma, en su apartado g, dispone que "a los efectos del presente Estatuto se entenderá que el término género se refiere a los dos sexos, masculino y femenino, en el contexto de la sociedad. El término género no tendrá más acepción que la que antecede"

${ }^{54}$ Artículos 42.9, 54.1.b, 68.1 respectivamente.

${ }^{55}$ PASCUAL I LAGUNAS, E. “La violencia sexual en los conflictos armados...”, Op. Cit., p. 292.
} 
sólo lo circunscribe, sino que también lo condiciona ${ }^{56}$. Para Elrich "el centro de gravedad de la evolución del Derecho no se halla en la legislación, en la ciencia jurídica ni en la jurisprudencia, sino en la misma sociedad"57. Ciertamente, la llegada del Derecho Internacional al problema de las violencias específicas que enfrentan las mujeres durante las guerras no se habría producido sin la progresiva (y previa) concienciación social sobre la situación de la mujer que se ha ido consolidando en las últimas décadas. El impuso definitivo que experimentó el Derecho Internacional gracias a la labor de los tribunales penales internacionales para Ruanda y la ex Yugoslavia fue posible por la existencia de un clima de concienciación y que permitió, por un lado, la incorporación de la violencia sexual a las agendas políticas de $\operatorname{los}$ Estados $^{58} \mathrm{y}$, por otro, la tipificación de la violencia sexual como delito internacional en los Estatutos de los diferentes tribunales penales internacionales. Pero, a pesar del histórico avance social, político y jurídico que supuso la consideración de la violencia sexual como crimen internacional bajo distintas fórmulas, conviene no dejar nunca de cuestionar y problematizar el enfoque jurídico.

Uno de los desafíos más complejos que afronta el Derecho Internacional en relación al tratamiento de la violencia sexual contra las mujeres es el de la superación del paradigma que reproduce una única imagen de la mujer: el de víctima. Desde un punto de vista jurídico, el reconocimiento del estatus o condición de víctima y de la existencia de grupos especialmente vulnerables a determinadas violencias no es en sí mismo problemático ni negativo; es incluso una condición necesaria para la ulterior protección jurídica. Pero "reconocimiento de las víctimas" no es lo mismo que "victimización". El ordenamiento jurídico internacional se ha centrado, efectivamente, en reconocer la vulnerabilidad de la mujer, pero ha faltado quizás entender o subrayar que esta vulnerabilidad no es intrínseca a la mujer o al hecho de ser mujer, sino que es fruto de unas estructuras y dinámicas sociales discriminatorias anteriores a la guerra pero exacerbadas con la guerra- que configuran un marco social y cultural en el que se generan y propician estas desigualdades y estas vulnerabilidades. $\mathrm{Y}$ en pocos contextos esos

\footnotetext{
${ }^{56}$ CAMPIONE, R., "Estructura y Función: la filosofía del derecho como teoría social”, Rivista Internazionale di Filosofia del Diritto, Serie V, Anno LXXXV, No. 4, Octubre/Noviembre 2008, pp. 613-668.

${ }^{57}$ EHRLICH, E., I fondamentidella sociología del diritto, Milán, Giuffré , 1976, p.3.

${ }^{58}$ La Cuarta Conferencia Mundial sobre la Mujer, celebrada en Beijing en 1995, marcó un importante punto de inflexión para la agenda mundial de igualdad de género. La Declaración y Plataforma de Acción de Beijing, adoptada de forma unánime por 189 países, constituye un programa en favor del empoderamiento de la mujer y en su elaboración se tuvo en cuenta el documento clave de política mundial sobre igualdad de género. Véase https://www.unwomen.org/es/how-we-work/intergovernmental-support/world-conferences-on-women. Documento disponible en https://www.unwomen.org/-/media/headquarters/attachments/sections/csw/bpa_s_final_web.pdf?la=es\&vs=755
} 
roles y dinámicas de subordinación, objetualización y sexualización de la mujer se exacerban tanto como en las guerras que, además, como se ha señalado, implican otras formas brutales de violencia bélica.

Existen numerosas discusiones acerca de cómo configurar un mejor estatus de la mujer en el derecho bélico que la presente (o represente) como agente activo y a la vez sujeto de protección específica. Como señala Amy Barrow, "la construcción del género en el Derecho Internacional Humanitario adolece de numerosas limitaciones sin que exista una forma radical de resolverlas" 59 . Reconocer, criminalizar y castigar la violencia sexual contra las mujeres durante las guerras representa un éxito sin precedentes, pero no podemos ignorar los problemas asociados a la reproducción de la imagen única de la mujer como víctima. Es hora de buscar un estatus que incorpore más fidedignamente la realidad de la mujer. Éste es un desafío particularmente espinoso en el ámbito del DIH, pues estamos ante un ordenamiento que, por su propia naturaleza y razón de ser, se encuentra en permanente búsqueda de categorías universales mientras que, en la práctica, dichas categorías están siendo constantemente cuestionadas y desafiadas. Basta con pensar en la actual crisis y cuestionamiento de categorías típicas del DIH como "guerra", "paz", “conflicto armado internacional”, “enemigo", "combatiente”, “civil”... para darnos cuenta del reto que supone configurar categorías universales y, sobre todo, de la dificultad que conlleva resistir los contantes embistes fruto de la naturaleza fluctuante de la conflictividad internacional. En el contexto internacional actual, abordar situaciones de violencia sexual contra las mujeres en tiempos de guerra remitiéndonos continuadamente a los Convenios de Ginebra va a resultar costoso en la medida en que dicho marco jurídico hace referencia a un tipo de guerra y a una serie de categorías que deben ser (o deberían ser) identificables y delimitables pero que hoy, más que nunca, se están desvaneciendo.

Junto a los desafíos que existen desde el ámbito del Derecho Internacional Humanitario, no podemos olvidar aquellos que están vinculados con el Derecho penal internacional. Abordar el problema de la violencia sexual contra las mujeres durante las guerras desde una vertiente meramente delictiva y punitiva, conlleva el riesgo de perpetuar, expandir y ampliar el derecho penal y las políticas de seguridad. Cualquier expansión de los paradigmas securitarios y punitivistas comporta una serie de

59 BARROW, A., "UN Security Council Resolutions 1325 and 1820: constructing gender in armed conflict and international law", International Review of the Red Cross, Vol. 92, No. 877, March 2010, p. 17. 
peligros para las garantías y derechos fundamentales que tienen que ver sin duda con la clase de Estado de Derecho que aspiramos a construir. Los actos de violencia sexual durante las guerras (al igual que ocurre con la tortura, tratos inhumanos, crímenes de lesa humanidad y otros crímenes de guerra) son delitos cuyos daños y efectos trascienden a la propia víctima y se prolongan en el tiempo y el espacio sobre la familia, sobre la comunidad y sobre la sociedad en su conjunto. Es por esos que los esquemas punitivistas, por sí solos, nunca podrá retribuir el daño causado, y nunca podrán actuar sobre las causas estructurales de estas violencias. Debemos sin duda reconocer y reivindicar la importancia y la función trasformadora de la justicia penal internacional en relación a la violencia sexual a través de la definición, tipificación y persecución de dichos delitos. Los procesos penales pueden servir para rehabilitar sociedades rotas por los conflictos y las violaciones masivas de derechos humanos ${ }^{60}$. Pero ni la justicia internacional debe agotar su labor en el enjuiciamiento y castigo de los culpables, ni debemos buscar las soluciones únicamente en el Derecho Internacional Penal. Es en última instancia responsabilidad de los gobiernos, las instituciones y los ciudadanos combatir las causas estructurales que alimentan los sistemas de desigualdad social, discriminación y pobreza que son caldo de cultivo para las múltiples dimensiones de la violencia que sufrirán los civiles en caso de conflicto armado.

\footnotetext{
${ }^{60}$ Puede verse más acerca de los problemas de un enfoque exclusivamente retributive en DE GUZMAN, M.M., "An expressive rationale for the thematic prosecution of sex crimes", en MORTEN, B., Thematic Prosecution of International Sex Crimes, Torkel Opsahl Academic Epublisher 2012, pp. 11-44, en las páginas 16-28.
} 


\section{Referencias bibliográficas}

ALDAVE, A. "La crisis de la noción tradicional de conflicto armado en Derecho Internacional: ¿vestigio de una realidad extinta?" en CAMPIONE, R. y RUSCHI, F., Guerra, Derecho y Seguridad en las Relaciones Internacionales, Valencia, Tirant lo Blanch, 2017, pp. 21-44.

ASKIN, KELLY D., "Prosecuting Wartime Rape and Other Gender-Related Crimes under International Law: extraordinary advances advances, enduring obstacles”, Berkeley Journal of International Law, Vol. 21, Issue 2, 2003, pp. $288-349$.

BARROW, A., "UN Security Council Resolutions 1325 and 1820: constructing gender in armed conflict and international law”, International Review of the Red Cross, Vol. 92, No. 877, March 2010, p. 17.

CAMPIONE, R., "Estructura y Función: la filosofía del derecho como teoría social”, Rivista Internazionale di Filosofia del Diritto, Serie V, Anno LXXXV, No. 4, Octubre/Noviembre 2008, pp. 613-668.

CHINKIN, C., "Rape and Sexual Abuse of Women in International Law”, European Journal of International Law, Vol. 5, No. 2, 1994, pp. 326-341.

CHUNG, H. y SARAH SOH, C., «The Comfort Women: Sexual Violence and Postcolonial Memory in Korea and Japan», American Anthropologist, Vol. 112, No. 2, 2010, pp. 337-338.

COHN, C., "Hacia un marco conceptual de la violencia contra las mujeres en las guerras" en COHN, C., (ed.) Women and Wars, Polity Press Ltd. Cambridge, 2014. Edición española Las mujeres y las guerras, Ed. ICIP, Barcelona 2015.

DE GUZMAN, M.M., “An expressive rationale for the thematic prosecution of sex crimes”, en MORTEN, B., Thematic Prosecution of International Sex Crimes, Torkel Opsahl Academic Epublisher 2012, pp. 11-44.

EHRLICH, E., I fondamenti della sociología del diritto, 1976, Milán, Giuffré, p.3.

FUSCO, C., "Invasion of Space by a Female”, en FRIEDMAN, J. y VALENTI, J. (eds.) Yes means yes! Visions of Female Sexual Power and a World without Rape, Berkeley, Seal Press, 2008, pp.127-139.

GOLDSTEIN, J., War and Gender: How Gender Shapes the War System and Viceversa. Cambridge, Cambridge University Press, 2001.

LIVIO, T., Historia de Roma desde su fundación. Vol. 1, Libros I a X, Ab urbe condia,

NAIMARK, N., The Russians in Germany: A History of the Soviet Zone of Occupation, 1945-1949. Boston, Boston Harvard University Press, 1995.

PASCUAL I LAGUNAS, E., "La violencia sexual en los conflictos armados: una reflexión crítica sobre su configuración jurídica, jurisprudencial y doctrinal”, Universidad Autónoma de Barcelona, 2017.

PEARCE, J., "Bringing violence 'back home': Gender socialization and the transmission of violence through time and space”, en ANHEIER H. K., KALDOR, Mary y GLASIAUS, M. (eds.) Global Civil Society, 2006/7, Londres, Sage Publications, pp. 42-60..

RAYAS, L., "Las mujeres soldadas en las nuevas guerras de los siglos XX y XXI” en QUESADA, F. (ed.), Mujeres y guerra. Cuerpos, territorios y anexiones, Madrid, Biblioteca Nueva, 2014, pp. 229-257.

RIOS, J. y BROCATE, R., "Violencia sexual como crimen de lesa humanidad: los casos de Guatemala y Perú", Revista CIDOPB d'Afers Internacionals, No. 117, pp. 79-99, p. 85. 
ROBERT LILLY, J.,Taken by Force: Rape and American Girls in Europe during World War II, Londres, Palgrave Macmillan, 2007

SÁNCHEZ DE MADARIAGA, E., "Género y guerras: la criminalización de la violencia sexual”, Journal of Feminist, Gender and Women Studies, Vol 3, 2016, pp. 45-55.

SARAH SOH, C., «The Comfort Women: Sexual Violence and Postcolonial Memory in Korea and Japan», American Anthropologist, Vol. 112, No. 2, 2010

SIVAKUMARAN, S., "Sexual violence against men in armed conflict", European Journal of International Law, Vol. 18 (2), 2007, pp. 253-276

SLAUGHTER A.M., "Definig the limits: Universal Jurisdiciion and International Courts", en MACEDO, S. (ed.), Universal jurisdiction: national courts and the prosecution of serious crimes under international law,,Philadelphia, University of Pennsylvania Press, 2006, pp. 168-190.

STRAUS MURRAY, A., "Thirty years of denying the evidence on gender simmetry" en Partner Violence: implications for prevention and treatment. Partner Abuse, Vol. 1, 2010, pp. 332-362.

WOOD, E.J., "Rape During War is not Inevitable: Variation in Wartime Sexual Violence" en BERGSMO, M., BUTENSCHON, A., WOOD, E.J. (eds.), Understanding and Proving International Sex Crimes, Beijing, Torkel Opsahl Academic Epublisher, 2012, pp. 289-419. 